\title{
Road traffic injuries in Rawalpindi city, Pakistan
}

\author{
U. Farooq, ${ }^{7}$ J.A. Bhatti, ${ }^{2}$ M. Siddiq, ${ }^{7}$ M. Majeed, ${ }^{1}$ N. Malik, ${ }^{1}$ J.A. Razzak ${ }^{3}$ and M.M. Khan ${ }^{1}$
}

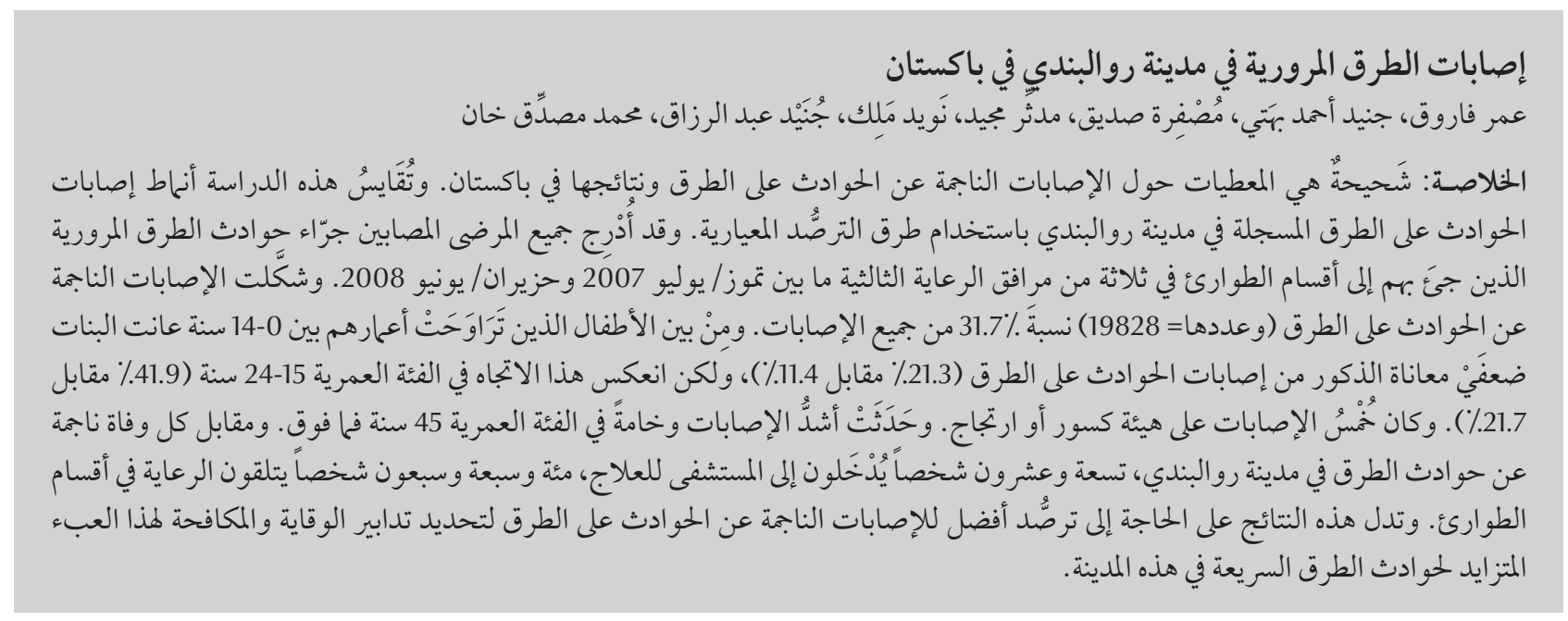

ABSTRACT Data on road traffic accident (RTA) injuries and their outcome are scarce in Pakistan. This study assessed patterns of RTA injuries reported in Rawalpindi city using standard surveillance methods. All RTA injury patients presenting to emergency departments of 3 tertiary care facilities from July 2007 to June 2008 were included. RTA injuries ( $n=19828$ ) accounted for $31.7 \%$ of all injuries. Among children aged $0-14$ years females suffered twice as many RTA injuries as males (21.3\% versus $11.4 \%)$, whereas this trend reversed for the age group $15-24$ years (41.9\% versus $21.7 \%$ ). One-fifth of injuries were either fractures or concussion. Severity and outcome of injuries were worse for the age group 45 years and older. For every road traffic death in Rawalpindi city, 29 more people were hospitalized and 177 more received emergency department care. These results suggest the need for better RTA injury surveillance to identify preventive and control measures for the increasingly high road disease burden in this city.

\section{Traumatismes dus aux accidents de la circulation dans la ville de Rawalpindi (Pakistan)}

RÉSUMÉ Les données sur les traumatismes dus aux accidents de la circulation et leurs suites sont rares au Pakistan. La présente étude a évalué les caractéristiques des traumatismes dus aux accidents de la circulation notifiés dans la ville de Rawalpindi à l'aide de méthodes de surveillance classiques. Tous les patients souffrant de traumatismes dus à un accident de la circulation se présentant aux services des urgences dans trois établissements de soins tertiaires entre juillet 2007 et juin 2008 ont été inclus dans l'étude. Les traumatismes dus aux accidents de la circulation ( $n=19828)$ représentaient 31,7\% de l'ensemble des traumatismes. Jusqu'à 14 ans, les filles souffraient deux fois plus de traumatismes dus aux accidents de la circulation que les garçons (21,3\% contre $11,4 \%$ ), alors que cette tendance s'inversait dans le groupe d'âge des 15-24 ans (41,9\% par rapport à 21,7 \%). Un cinquième des traumatismes étaient soit des fractures, soit des commotions. La sévérité des traumatismes s'intensifiait et leurs suites s'aggravaient dans le groupe d'âge des 45 ans et plus. Pour chaque décès causé par un accident de la circulation dans la ville de Rawalpindi, 29 personnes étaient hospitalisées et 177 autres recevaient des soins aux services des urgences. Ces résultats font ressortir la nécessité d'une meilleure surveillance des traumatismes dus aux accidents de la circulation pour identifier des mesures de prévention et de lutte visant à réduire leur charge de morbidité croissante dans la ville

${ }^{7}$ Department of Surgery, Holy Family Hospital, Rawalpindi, Pakistan (Correspondence to U. Farooq: dr_umar_farooq@yahoo.com). ${ }^{2}$ Injury Prevention and Control Research Team, National Institute of Health and Medical Research (INSERM U897), Université Bordeaux Segalen, Bordeaux, France.

${ }^{3}$ Department of Emergency Medicine, The Aga Khan University, Karachi, Pakistan

Received: 28/10/09; accepted: 21/02/10 


\section{Introduction}

Injuries due to road traffic accidents (RTAs) are a global public health problem [1] that disproportionately affects low-and middle-income countries (LMICs) which account for more than $90 \%$ of road fatalities [2]. In the Eastern Mediterranean region (EMR) 30\% of all injury-related deaths in 2004 were due to RTAs [3]. The RTA mortality rate was estimated at 32.2 deaths per 100000 population in LMICs of EMR, a rate twice as high as European LMICs [4]. It is projected that road accident fatalities in EMR will increase by $68 \%$ from 1990 to 2020 [5].

Pakistan constitutes a major workforce of the EMR [6]. In the absence of effective rail and urban transport, more than $90 \%$ of passenger and goods transport goes by road in $\mathrm{Pa}-$ kistan [7]. With the recent expansion in economic development and ease of obtaining car loans, the rate of vehicle production over the period from 2001 to 2006 increased by over $300 \%$ to meet consumer demands [8]. In Pakistan, it is estimated that injuries generally, and RTA injuries in particular, may have led to increased loss of daily adjusted life years [9]. However, official reports indicated that only 7000 RTA fatalities occur each year in Pakistan [6]. A recent report estimated 41000 RTA fatalities occur each year in Pakistan, 24\% of all estimated fatalities in EMR [4].

A better description of RTA injuries, particularly of non-fatal ones is essential for injury prevention and control measures [10]. Police data, which are often the only source of assessing the burden of RTA in LMICs, highly underestimate non-fatal injuries $[1,11]$. For instance, as compared with ambulance logs, police registered only $4 \%$ of non-fatal RTA injuries in Karachi, Pakistan [12]. Hospital data are an alternative to police statistics in assessing patterns of RTA injuries [13]. Previous research in Pakistan has demonstrated the limitations of estimating RTA injuries using hospital logs only $[14,15]$. Indeed, emergency department logs have to be modified in order to collect related information [16]. This study assessed the patterns of RTA injuries in an urban town of Pakistan over a 1-year period using standard surveillance methods.

\section{Methods}

\section{Study setting}

The study setting was Rawalpindi city, a predominantly urban sub-district situated in the north of the province of Punjab. According to the 1998 census, this sub-district had a population of 1.9 million dispersed over $1682 \mathrm{~km}^{2}$ $[17,18]$. Emergency care to RTA injury victims is provided by the nearest public sector health facility. Moderate to severe injuries from all over the city and other parts of the district are referred to 3 major tertiary care facilities: Holy Family hospital, Benazir Bhutto Shaheed hospital (formerly called Rawalpindi general hospital) and the district headquarters hospital. These hospitals offer 24-hour accident and emergency (A\&E) and medicolegal services. Since August 2007, a public sector pre-hospital emergency care system also exists in Rawalpindi and Murree sub-districts, transporting RTA injury victims directly to these nearby public hospitals.

\section{Study design}

A cross-sectional study design was used. All patients presenting to the A\&E departments of the 3 hospitals with an injury-related problem, who had received an emergency visit slip were included in this study. The study duration was 1 year from 1 July 2007 to 30 June 2008. The study was approved by the institutional review board of the Rawalpindi Medical College and the 3 teaching hospitals.

\section{Measures}

The measurement tool was the minimal data set questionnaire for injury surveillance recommended by the World Health Organization (WHO) [19]. This includes age and sex of the victim and the place, activity, mechanism, nature, severity and outcome of the injury. Injury severity was defined as mild (minor or superficial such as bruise or cut), moderate (requiring some skilled treatment such as in case of fractures or sutures) or severe (requiring intensive medical or surgical management such as in case of internal haemorrhage, punctured organs, severe blood vessels) [19]. This 1-page questionnaire was translated into Urdu and was back translated to English to ensure consistency. The questionnaire was filled by a face-to-face interview after initial management of the patients and obtaining their informed consent for participation.

\section{Data collection}

Data collection was coordinated at the hospital level by one surgery resident. Four data collectors from the attending hospital staff were nominated in each department to ensure data collection 24 hours a day. A central research coordinator (registrar in the department of surgery) along with the head of the department of surgery supervised this process. Every day, all questionnaires filled during the previous 24 hours were submitted to the directors of the A\&E departments. These were transferred to a central coordination office every third day. These were then coded using Epi-Info software, version 3.5.1 by 2 data entry operators. The coordinating officers (registrars and residents) checked 10\% of the data during coding and entry to detect errors during these steps. Ethical approval of the study protocol was obtained from Rawalpindi Medical College research ethics council before the conduct of the study. 


\section{Analysis}

All those reporting a RTA injury were selected for further data analysis. Mean ages for men and women presenting with RTA injury were computed. Age and sex patterns of RTA injuries were studied using World Health Organization (WHO) categories [19]. For simplicity, the relationship of age with other variables such as site, activity, alcohol use, injury severity and type of injuries was further studied in 3 age categories: $0-15$ years, $16-45$ years, and $>45$ years. Proportions within categories were compared with the chi-squared test for trend where appropriate.

\section{Results}

Out of 62530 patients reporting injuries in 1 year, 19828 (31.7\%) were injured due to RTAs. Rawalpindi general hospital received $43.7 \%(n=8657)$ of these patients, district headquarters hospital 31.9\% $(n=6319)$ and Benazir Bhutto Shaheed hospital 24.5\% ( $n=$ 4853). Most of the injured patients were males $(89.1 \%, n=17684)$. The mean age of males presenting with RTA injuries was 26.1 [standard deviation (SD) 13.2] years whereas it was 29.2 (SD 17.4) years in females. The highest rate of injuries in both sexes was age group $15-44$ years $(76.5 \%$ of males and $56.4 \%$ of females). RTA injuries were twice as high in girls $(0-14$ years $)$ than boys $(21.3 \%$ versus $11.4 \%)(P<0.001)$. In the age group 15-24 years, however, RTA injuries were twice as high in men $(41.9 \%)$ compared with women (21.7\%) and this was significantly different compared with other age groups $(P$ $<0.001$ ) (Figure 1).

Besides roads ( $91.3 \%$ of males and $87.5 \%$ of females), markets were common sites of these injuries (5.0\% and $4.9 \%$ of males and females respectively) (Table 1). For the age group $0-15$ years, slightly fewer RTA injury were reported on roads as compared with the overall trend ( $87.2 \%$ versus $91.3 \%$ of boys and $82.5 \%$ versus $87.5 \%$ of girls) $(P<$ $0.001)$. The commonest activity during a RTA injury was travelling (93.7\% of males and $90.4 \%$ of females). In the age group $0-15$ years, significantly more of the patients had a RTA injury during a sports-related activity as compared with the overall trend ( $8.1 \%$ versus $2.2 \%$ of boys and $12.1 \%$ versus $4.3 \%$ of girls) ( $P$ $<0.001)$.

Few patients $(0.3 \%)$ reported to be under the influence of drugs or alcohol during a crash: 7 times more men $(n=$ 48) than women $(n=7)$.

Most of the injuries sustained during the RTA were classified as mild ( $53.7 \%$ of males and $47.5 \%$ of females) or moderate (42.0\% of males and $45.9 \%$ of females). The proportion of injuries that were graded as severe was twice as high in females as compared to males (3.2\% versus $1.8 \%$ ). Similarly, the severity of injuries in men and women $>45$

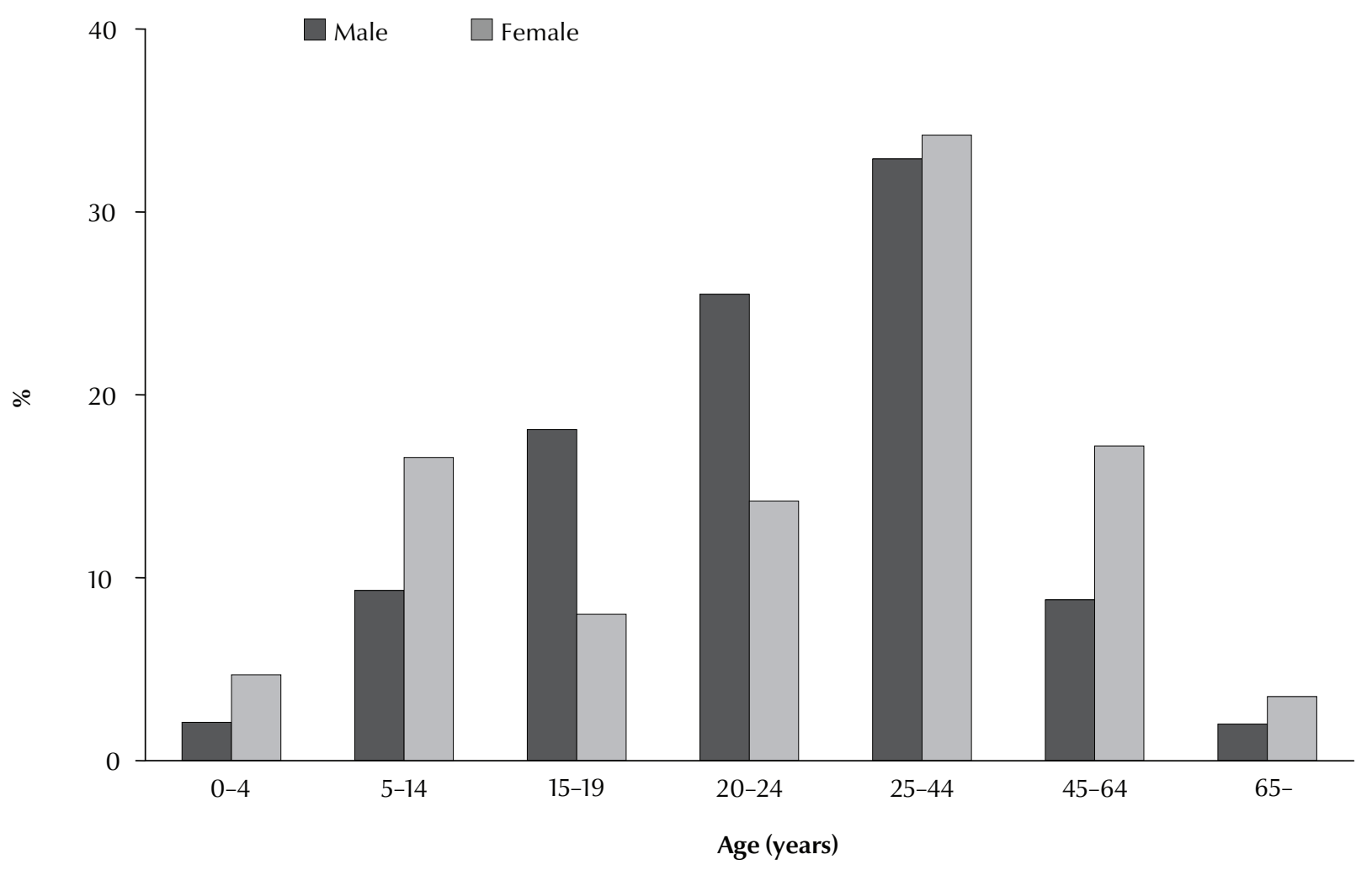

Figure 1 Age and sex patterns of road traffic injuries in Rawalpindi (July 2007-June 2008) 


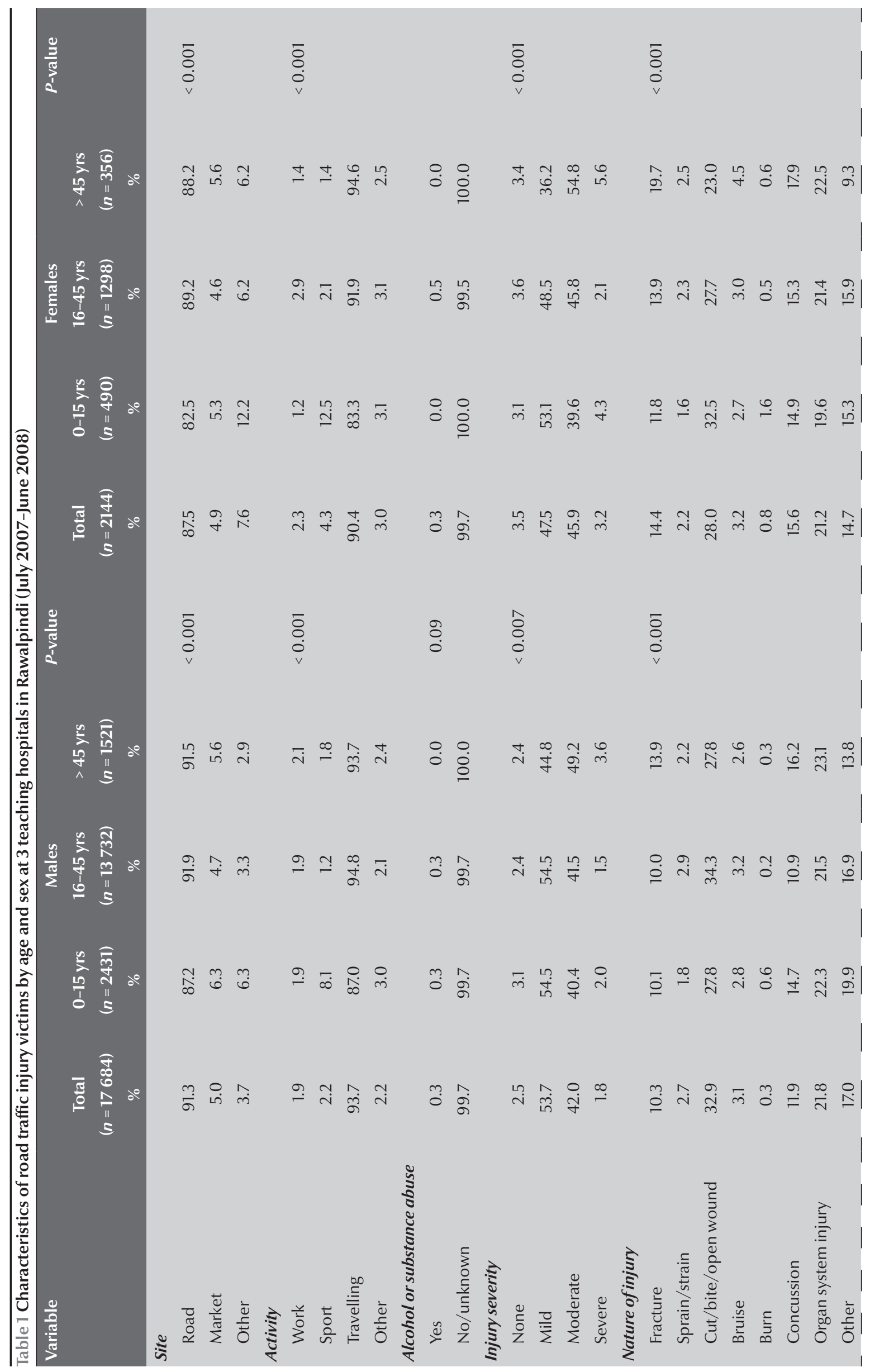




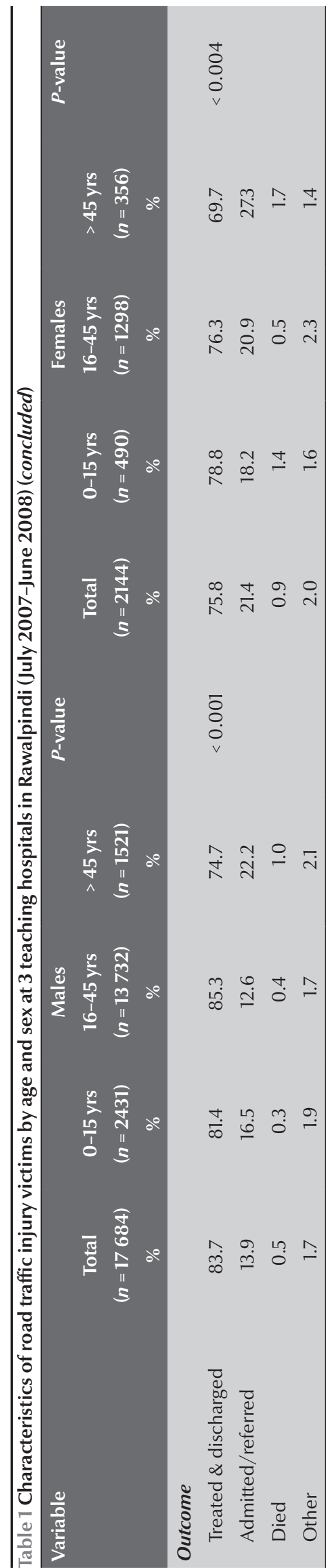

years was significantly higher than the overall trend $(3.6 \%$ versus $1.8 \%$ of males and $5.6 \%$ versus $3.2 \%$ of females $)(P<$ 0.001 ).

Minor cuts and bruises were the commonest type of injury as a result of a road crash (32.9\% of males and $28.0 \%$ of females). Fractures were one of the major types of RTA injury (10.3\% of males and $14.4 \%$ of females), so too was concussion (11.9\% of males and $15.6 \%$ of females). Those aged $>45$ years sustained significantly more fractures compared with the overall trend (13.9\% versus $10.3 \%$ of men and $19.7 \%$ versus $14.4 \%$ of women $)(P<0.001)$.

A majority of the male (83.7\%) and female $(75.8 \%)$ patients were treated and discharged from the A\&E department. A total of 84 males $(0.5 \%)$ and 19 females $(0.9 \%)$ died as a result of RTA in the A\&E departments of these hospitals. Mortality was higher for those aged $>45$ years as compared with general trend $(1.0 \%$ versus $0.5 \%$ of males and $1.7 \%$ versus $0.9 \%$ of females).

\section{Discussion}

The previous literature has identified RTAs as one of the leading causes of injuries in Pakistan [20-22]. These results showed that indeed RTA injuries accounted for nearly one-third of injuries (31.7\%) for which patients sought care in A\&E departments of tertiary care facilities of Rawalpindi city. Our results were consistent with previous findings that $30 \%-86 \%$ of trauma admissions in LMICs were due to RTA injuries $[1,23]$. Indeed, RTA injuries engage significant amounts of human and physical resources of the health systems in LMICs. Prevention of these injuries can play an important role in improving the capacity of the health care systems.

The mean age of RTA patients was 26.1 (SD 13.2) years in males and 29.2 (SD 17.4) years in females. These results are similar to previously findings from a population-based survey of injuries, where the mean age of those reporting injuries in the previous 3 months was 23.9 (SD 18) years [22]. It is likely that these RTA injuries were a major source of direct and indirect economic costs in this subdistrict.

Our study confirmed other research showing that children are the second most vulnerable group for RTA injuries in South-East Asia including Pakistan $[21,24,25]$. We also showed that girls were more likely to be involved in a RTA injury than were boys. A previous study showed that girls in Pakistan were more likely to develop disability after suffering an injury [21]. These results suggested that factors associated with female injuries should be identified in order to develop preventive strategies. In children, sport was the major activity during a RTA injury, after travelling.

The highest proportion of the injury patients were aged $15-44$ years and for this age group, twice as many men were involved in a RTA compared with women. The predominance of adult men involved in RTA injuries can be explained by their gender roles [22]. Indeed, men are the main earners for the family and therefore involved usually in outdoor activities exposing them to RTAs. Previous research showed that $63 \%$ of neurosurgical fatalities resulted from RTAs involving those aged $<40$ years old were due to head injuries [26]. Pakistan has a high dependency ratio, and unintentional loss of a life not only contributes to overall economical loss in terms of gross domestic product but also has a detrimental impact on the economy of individual families. This clearly indicates the need for more efforts to prevent RTA injuries in Pakistan.

Deaths from RTA in the A\&E departments of these hospitals were recorded in $0.5 \%$ of males and $0.9 \%$ of females. The severity and outcome of injuries, including deaths, was worse for 
age group $>45$ years as compared with the overall trend.

Driving under the influence of alcohol or other substances is a major contributing factor to RTAs [1]. Previous research in South Africa has shown that alcohol was a contributing factor in $47 \%$ of fatal and $27 \%$ of non-fatal crashes; high alcohol was found in the blood of $52 \%$ of people involved in road crashes [27,28]. In New Delhi, India, a study found that one-third of riders of motorized 2-wheeler vehicles reported driving while intoxicated [29]. Very few patients in our study reported being under the influence of drugs or alcohol. It is possible, however, that this was under-reported due to the stigma of alcohol use at in Pakistani society. Little information is available in Pakistan about alcohol abuse in general and about driving while intoxicated in particular $[6,20]$. More efforts are required to assess the prevalence of substance abuse and its relationship to RTA injuries in Pakistan.

Our results showed that cuts and open wounds were the commonest injuries, followed by fractures and head and neck injuries including concussion. A study from urban India showed that bone fracture was the most common injury to patients, followed by multiple injuries such as blunt injury, abrasions and lacerations [30]. Studies from both Pakistan and India showed that extremity injuries were the most common, followed by head and face and then chest injuries $[31,32]$. This type of information is often unavailable in LMICs, yet it can be useful for organizing health care services.

This study had several limitations. Injury surveillance was performed only in selected tertiary care hospitals. It is possible that RTA injuries of a minor nature which occurred away from city centres were not accounted for. Therefore, we were unable to present overall injury rates and mortality rates in this district. Moreover, the outcome of injuries was based only on the information available in the A\&E department and patients were not followed up due to the limited resources available for the study. Nevertheless, more detailed data about injuries was recorded in this study than are routinely available $[12,14]$.

The population of Pakistan has increased from 136 million in 1999 to 162 million in 2008 [33]. The increase was twice as high in urban than rural areas ( $28 \%$ versus $14 \%$ ). Similarly, the road transport needs in the country are expected to double from 2005 to 2015 [7]. This urban population growth, coupled with an expected increase in road transport, will certainly lead to an increase in RTA injuries in Pakistani cities such as Rawalpindi [3,4]. Improved continuous surveillance is thus essential for policymaking in order to reduce this expected escalation in road disease burden [1]. Our results indicate that hospital-based injury surveillance is practical and can provide useful information in the Pakistani setting. However, such efforts need to be the part of a political road safety agenda so that preventive actions can be taken in a more effective way $[34,35]$.

\section{Conclusions}

For every road traffic death in Rawalpindi city, 29 other persons were hospitalized, and 177 more received emergency department care. The results point to an increased road disease burden in Pakistan which needs immediate attention in the political agenda $[3,10]$. Moreover, these results suggest the need for a comprehensive RTA injury surveillance in this city to better identify road user types, sites and situational factors involved in these crashes. This could help to implement and evaluate traffic engineering and enforcement measures in this city. Further, road safety education programmes in schools and provision of adequate sports facilities could prevent a significant proportion of RTA injuries in children.

\section{Acknowledgements}

We are grateful to the emergency staff, director emergency, and medical superintendent of the teaching hospitals for their cooperation during the study. We highly appreciate the Government of Punjab for taking initiative to collect data on injuries. This study was funded by the Government of Punjab, Pakistan. Funding organization had no input in study design, conception, and the conduct of the study.

\section{References}

1. Peden $\mathrm{M}$ et al. World report on road traffic injury prevention. Geneva, World Health Organization, 2004.

2. Jacobs G, Aeron-Thomas A, Astrop A. Estimating global road fatalities. Crowthorne, United Kingdom, Transport Research Laboratory, 2000.

3. The global burden of disease: 2004 update. Geneva, World Health Organization, 2008.

4. Global status report on road safety. Geneva, World Health Organization, 2009.

5. Murray CJL, Lopez AD, eds. The global burden of disease: a comprehensive assessment of mortality and disability from dis- eases, injuries, and risk factors in 1990 and projected to 2020. Boston, Massachusetts, Harvard School of Public Health, 1996.

6. National action plan for prevention and control of non-communicable diseases and health promotion in Pakistan. Islamabad. Ministry of Health Government of Pakistan/World Health Organization Pakistan/Heartfile, 2004.

7. Pakistan transport plan study in the Islamic Republic of Pakistan. Islamabad, Japan International Cooperation Agency (JICA), National Transport Research Center (NTRC)/Ministry of Communications Government of Pakistan, 2007. 
8. Ahmed A. Road safety in Pakistan. Islamabad, National Road Safety Secretariat, Ministry of Communications, 2007.

9. Nishtar S et al. Injury prevention and control: National Action Plan for NCD Prevention, Control and Health Promotion in Pakistan. Journal of the Pakistan Medical Association, 2004, 54(Suppl. 3):S57-S68.

10. Mock C, Cherian MN. The global burden of musculoskeletal injuries: challenges and solutions. Clinical Orthopaedics and Related Research, 2008, 466:2306-2316

11. Wootton J, Jacobs GD. Safe roads: A dream or a reality? Crowthorne, United Kingdom, Transport Research Laboratory, 1996.

12. Razzak JA, Luby SP. Estimating deaths and injuries due to road traffic accidents in Karachi, Pakistan, through the capturerecapture method. International Journal of Epidemiology, 1998, 27:866-870

13. Razzak J, Marsh D, Stansfield S. District hospital based injury data-are they an option in a developing country? Injury Prevention, 2002, 8:345b-346b.

14. Bhatti MA et al. Road traffic injuries in Pakistan: challenges in estimation through routine hospital data. Journal of Ayub Medical College, Abbottabad, 2008, 20:108-111.

15. Razzak JA, Laflamme L. Limitations of secondary data sets for road traffic injury epidemiology: a study from Karachi, Pakistan. Prehospital Emergency Care, 2005, 9:355-360.

16. Williams JM et al. The emergency department log as a simple injury-surveillance tool. Annals of Emergency Medicine, 1995, 25:686-691.

17. Socioeconomic indicators at district level: Punjab. Islamabad, Federal Bureau of Statistics, Government of Pakistan, 2000.

18. Population and housing census 1998. Islamabad, Population Census Organization. Government of Pakistan; 1999.

19. Holder $\mathrm{Y}$ et al. Injury surveillance guidelines. Geneva, World Health Organization, 1999.

20. Fatmi $Z$ et al. Incidence, patterns and severity of reported unintentional injuries in Pakistan for persons five years and older: results of the National Health Survey of Pakistan 1990-94. BMC Public Health, 2007, 7:152.

21. Fatmi $Z$ et al. Incidence and patterns of unintentional injuries and resulting disability among children under 5 years of age: results from national health survey of Pakistan. Paediatric and Perinatal Epidemiology, 2009, 23:229-238.
22. Ghaffar A, Hyder AA, Masud TI. The burden of road traffic injuries in developing countries: the 1st national injury survey of Pakistan. Public Health, 2004, 118:211-217

23. Odero W, Garner P, Zwi A. Road traffic injuries in developing countries: a comprehensive review of epidemiological studies. Tropical Medicine \& International Health, 1997, 2:445-460.

24. Hyder AA et al. Global childhood unintentional injury surveillance in four cities in developing countries: a pilot study. Bulletin of the World Health Organization, 2009, 87:342-345.

25. Qureshi AF, Bose A, Anjum Q. Road traffic injuries. A new agenda for child health. Journal of the College of Physicians and Surgeons--Pakistan, 2004, 14:719-721.

26. Ghani E et al. Khaleeq-uz-Zaman. Road traffic accidents as a major contributor to neurological mortality in adults. Journal of the College of Physicians and Surgeons of Pakistan, 2003, 13:143-145.

27. Peden M. Injured pedestrians in Cape Town: the role of alcohol. South African Medical Journal, 1996, 16:1103-1105.

28. Peden M. Substance abuse and trauma in Cape Town. South African Medical Journal, 2000, 90:251-255.

29. Mishra BK, Banerji AK, Mohan D. Two-wheeler injuries in Delhi, India: a study of crash victims hospitalized in a neuro-surgery ward. Accident; Analysis and Prevention, 1984, 16:407-416.

30. Singh $\mathrm{H}$, Dhatarwal SK. Pattern and distribution of injuries in fatal road traffic accidents in Rohtak (Haryana). Journal of the Indian Academy of Forensic Medicine, 2004, 26:971-973.

31. Ganveer GB, Tiwari RR. Injury pattern among non-fatal road traffic accident cases: a cross-sectional study in central india. Indian Journal of Medical Sciences, 2005, 59:8-12.

32. Report of road injury surveillance project of Injury Research and Prevention Centre of JPMC, Karachi. Karachi, Road Injury Research and Prevention Centre, Jinnah Post Graduate Medical Centre, 2007.

33. Pakistan economic survey 2008-2009. Islamabad, Ministry of Finance, Government of Pakistan, 2009.

34. Novoa AN et al. Road safety in the political agenda: the impact of traffic injuries. Journal of Epidemiology and Community Health, 2011, 65:218e-225e.

35. Soori $\mathrm{H}$ et al. Road traffic injuries in Iran: the role of interventions implemented by traffic police. Traffic Injury Prevention, $2009,10: 375-378$. 